\title{
Co-simulation Research on Flow Pulsation Characteristics of Plunger Pump Based on AMESim and ADAMS
}

\author{
Wenxin Qian ${ }^{1, a, *}$, Qinhe Gao ${ }^{1, b}$, Xiangyang $\mathrm{Li}^{1, \mathrm{c}}$, Yining $\mathrm{Li}^{2, \mathrm{~d}}$ \\ ${ }^{1}$ Xi’an High-Tech Research Institute, Xi’an, Shaanxi, China \\ ${ }^{2} \mathrm{Xi}$ 'an Flight Automatic Control Research Institute of China Aviation Industry, Xi'an, Shaanxi, China \\ a 53873696@qq.com, ${ }^{\mathrm{b}}$ qhgao201@126.com, ${ }^{\mathrm{c}}$ lxy_leon@aliyun.com, ${ }^{\mathrm{d}}$ lyn33333@126.com \\ *corresponding author
}

Key words: Axial plunger pump; Co-simulation; Flow pulsation.

\begin{abstract}
Flow pulsation characteristic is the inherent characteristic of the axial plunger pump, and it is an important factor that affects the working performance and the stability of the hydraulic system. To reduce the flow pulsation of axial plunger pump, theoretical analysis of the motion characteristics and flow pulsation characteristic; The co-simulation model of axial plunger pump was established using ADAMS and AMESim, The influence of different structural parameters on the pulsation of axial plunger pump flow is analyzed by simulation, and the pulsation curves of different plunger diameter, speed and inclined plate are obtained.. The results show that the flow pulsation of the axial plunger pump increases with the diameter of the plunger, the speed and the inclination of the swashplate increases, and the results provide a reference for reducing the flow pulsation of the axial plunger pump.
\end{abstract}

\section{Introduction}

Axial plunger pump is to rely on the plunger in the cylinder plunger hole in the reciprocating motion, so that changes in the working chamber to achieve changes in oil and oil, and is widely used in various industries ${ }^{[1]}$. Since the hydraulic fluid discharged from the plunger pump is extruded in the form of a plunger, this working characteristic determines the flow pulsation characteristic at the outlet of the plunger pump. Flow pulsation has a large effect on the hydraulic system, and the pressure pulsation caused by it causes the hydraulic system to oscillate and even damage the hydraulic components. Therefore, it is very important to study the flow pulsation characteristics of the plunger pump ${ }^{[2]}$.

In the study of the pulsation characteristics of the flow of the plunger pump, the traditional physical experiment method, waste time, change the parameters or conditions are more difficult, and sometimes even impossible to achieve ${ }^{[3]}$.Therefore, we can set up a simulation model of the plunger pump on the computer, using simulation means to reduce the test cost and improve the test efficiency $^{[4]}$.

In order to improve the accuracy of the simulation results and make the model more realistic, this paper uses ADAMS to build the multi-body dynamics model of the plunger pump, and uses the AMESim to establish the hydraulic system model of the plunger pump. The two models were combined to establish the joint simulation model of machine - liquid integration of plunger pump

\section{Theoretical Analysis of Flow Pulsation Characteristics}

The core part of the plunger pump consists of plunger, shoe, cylinder, swash plate, as shown in Fig.1, set the ramp angle $\alpha$, take $O X Y Z$ coordinate system, And the starting point is calculated by the point A through the OXY plane. When the cylinder to the angular velocity of $\omega$ movement time $t$, the plunger ball center from point A to point B.In the OYZ plane, the projection of the center of the plunger ball moves from point $C$ to point $D$, then the center of the ball plunger coordinates is : 


$$
\left\{\begin{array}{l}
x=-R \tan \alpha \cos \varphi=-R \tan \alpha \cos \omega t \\
y=R \cos \varphi=R \cos \omega t \\
z=R \sin \varphi=R \sin \omega t
\end{array}\right.
$$

The axial velocity of the plunger relative to the cylinder bore is

$$
v_{x}=\frac{\mathrm{d} x}{\mathrm{~d} t}=\omega R \tan \alpha \sin \omega t
$$

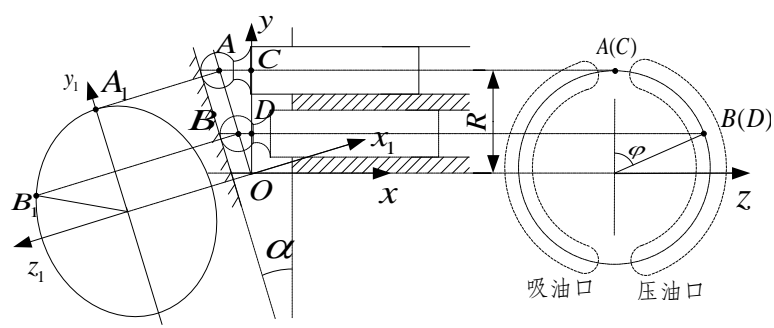

Fig.1 Plunger motion schematic.

Plunger pump in the course of operation, because the plunger speed is instantaneous change, and the number of plunger out of the area is also changing, so the plunger pump outlet flow is instantaneous change, and exists flow pulsation ${ }^{[5]}$.

The diameter of the plunger is $d$, the theoretical instantaneous flow rate of the single plunger is:

$$
q=\frac{\pi}{4} d^{2} v_{x}=\frac{\pi}{4} d^{2} \omega R \tan \alpha \sin \varphi
$$

The instantaneous flow of the pump should be the sum of all the instantaneous flow of the plunger in the drainage zone, which is:

$$
\begin{aligned}
Q & =\sum \frac{\pi}{4} d^{2} \omega R \tan \alpha \sin \varphi_{i} \\
& =\frac{\pi}{4} d^{2} \omega R \tan \alpha \sum \sin \varphi_{i}
\end{aligned}
$$

Set the number of plunger $n$, The angle of the plunger from the maximum extension position is $\varphi_{1}\left(0 \leq \varphi_{1} \leq 2 \pi / n\right)$, A total of $m$ plungers are located in the drainage area, the above formula can be rewritten as

$$
Q=\frac{\pi}{4} d^{2} \omega R \tan \alpha \sum_{i=1}^{m} \sin \left(\varphi_{1}+\frac{(i-1) \cdot 2 \pi}{n}\right)
$$

As the plunger pump plunger number is generally odd, the pump's theoretical instantaneous flow is:

So the pump flow rate is:

$$
Q=\left\{\begin{array}{l}
\frac{\pi}{4} d^{2} \omega R \tan \alpha \frac{\cos \left(\frac{\pi}{2 n}-\varphi_{1}\right)}{2 \sin \frac{\pi}{2 n}} ; 0 \leq \varphi_{1} \leq \frac{\pi}{n} \\
\frac{\pi}{4} d^{2} \omega R \tan \alpha \frac{\cos \left(\frac{3 \pi}{2 n}-\varphi_{1}\right)}{2 \sin \frac{\pi}{2 n}} ; \frac{\pi}{n} \leq \varphi_{1} \leq \frac{2 \pi}{n}
\end{array}\right.
$$

$$
\begin{aligned}
\delta & =\frac{Q_{\max }-Q_{\min }}{\frac{1}{2}\left(Q_{\max }+Q_{\min }\right)} \\
& =2 \tan ^{2} \frac{\pi}{4 n} \cdot 100 \%
\end{aligned}
$$

The equations (6) show that as the number of plungers increases, the flow rate pulsation decreases, But when $n \geq 9$, the trend becomes more gentle, So the plunger number of the axial plunger pump is generally no more than nine ${ }^{[5]}$ 。 


\section{Establishment of Co-Simulation Model}

Plunger pump physical prototype is composed of mechanical systems and hydraulic system, so the joint simulation model should also include these two parts, the modeling program shown in Fig. ${ }^{[7]}$ 。

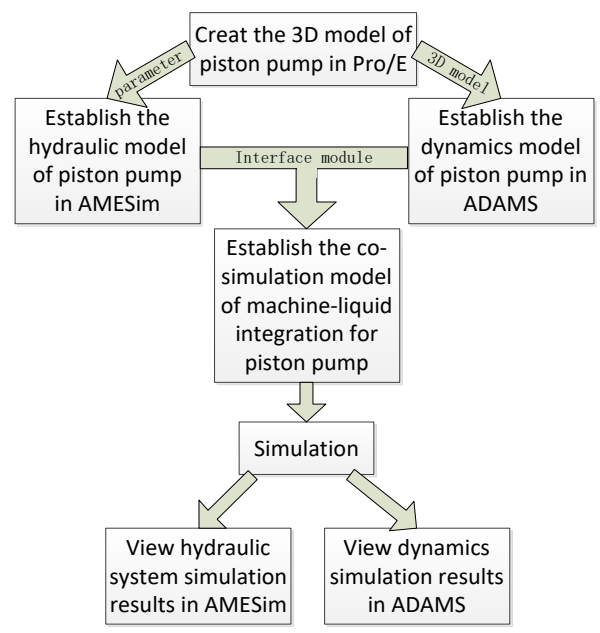

Fig.2 Co-simulation modeling scheme.

In this paper, the dynamic model and hydraulic model of the plunger pump are established in ADAMS and AMESim respectively. In order to establish the co-simulation model of the plunger pump, it is necessary to set the interface in ADAMS and AMESim respectively. After the interface is set up, the joint simulation model of the piston pump is established, and the simulation control is carried out by using the Simulation Contral tool in ADASM. as shown in Fig.3.

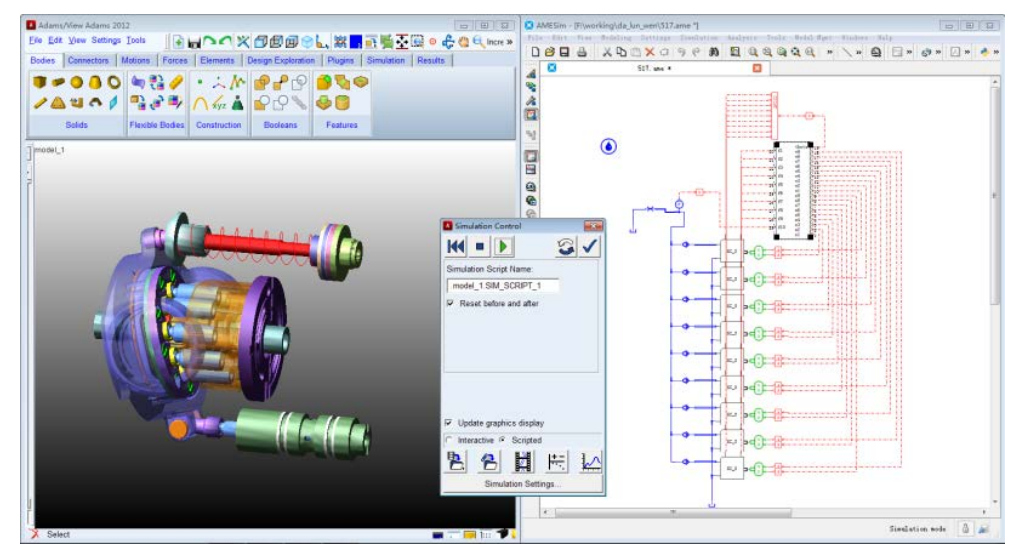

Fig.3 Co-simulation modeling.

\section{Simulation Results Analysis}

From the equations (6) can be seen to affect the plunger pump flow factors are plunger diameter, plunger pump speed, plunger distribution circle radius, swashplate inclination, and the plunger number. The influence of these factors on the flow pulsation of the plunger pump is studied from the three aspects of plunger diameter, plunger pump speed and swashplate inclination.

\subsection{Plunger Diameter}

In the established model of plunger pump joint simulation, the plunger diameter is set to $7 \mathrm{~mm}$, $8 \mathrm{~mm}, 9 \mathrm{~mm}, 10 \mathrm{~mm}$ and $11 \mathrm{~mm}$ respectively.other parameters remain unchanged, and then run the simulation, obtained the flow pulsation curve of plunger pump under different plunger diameter, as 
shown in Fig.4.

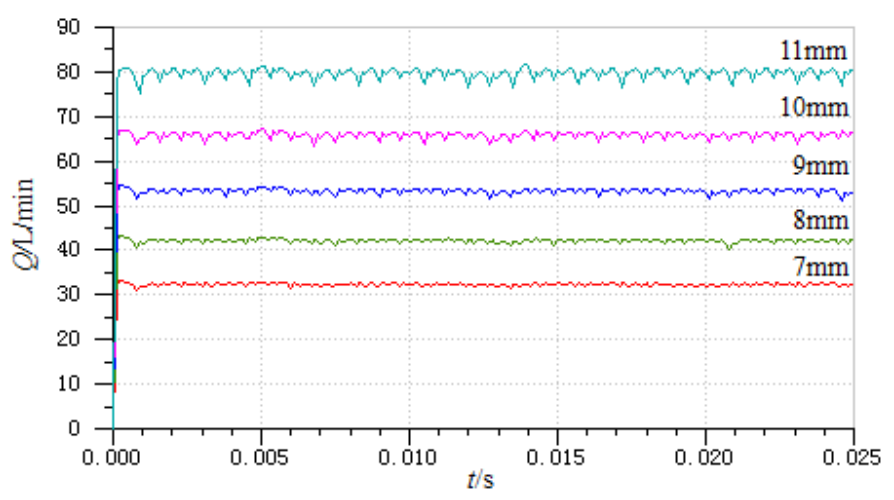

Fig.4 flow pulsation curve of plunger pump under different plunger diameters.

By analyzing the flow pulsation curve shown in Fig. 9, the flow pulsation rate of the plunger pump at different plunger diameters can be calculated according to the flow pulsation rate calculation formula, as shown in Table 1. It can be seen from the data in Table 3 that the flow pulsation rate of the plunger pump increases with the increase of the diameter of the plunger.Therefore, in the design of the plunger pump, reducing the plunger diameter can effectively reduce the flow pulsation of the plunger pump .

Table 1 flow pulsation rate of plunger pump under different plunger diameters.

\begin{tabular}{|c|c|c|c|c|}
\hline Plunger Diameter $(\mathrm{mm})$ & $Q_{\max }(\mathrm{L} / \mathrm{min})$ & $Q_{\min }(\mathrm{L} / \mathrm{min})$ & $Q_{\text {mean }}(\mathrm{L} / \mathrm{min})$ & $\delta(\%)$ \\
\hline 7 & 32.60 & 31.60 & 32.10 & 3.12 \\
\hline 8 & 42.60 & 41.20 & 41.90 & 3.34 \\
\hline 9 & 54.30 & 51.30 & 52.80 & 3.79 \\
\hline 10 & 67.20 & 63.50 & 63.35 & 5.84 \\
\hline 11 & 81.50 & 76.50 & 79.00 & 6.33 \\
\hline
\end{tabular}

\subsection{Plunger Pump Speed}

In the joint simulation model of the plunger pump, the speed is set to $1000 \mathrm{r} / \mathrm{min}, 3000 \mathrm{r} / \mathrm{min}$, $5000 \mathrm{r} / \mathrm{min}, 7000 \mathrm{r} / \mathrm{min}$ and $9000 \mathrm{r} / \mathrm{min}$ respectively, the other parameters are unchanged, The flow curve of the plunger pump at different rotational speeds is obtained, as shown in Fig.5

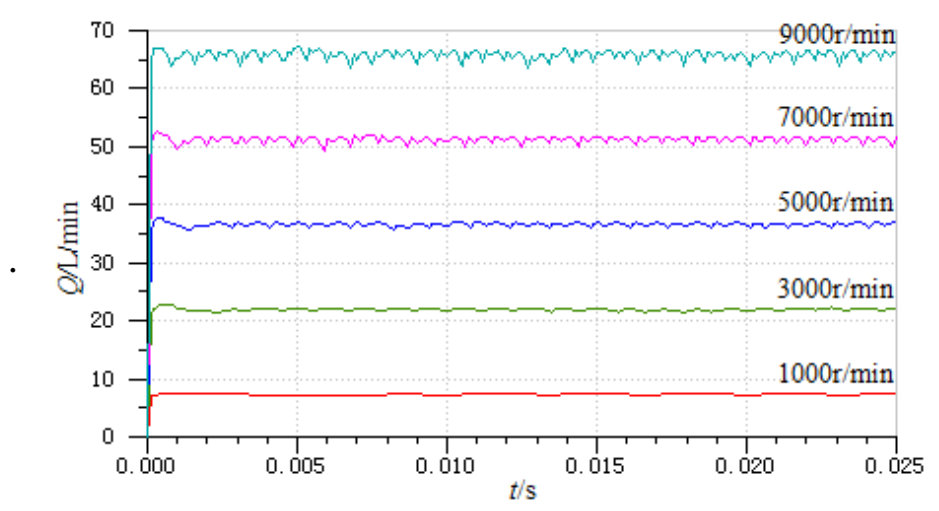

Fig.5 flow pulsation cure of plunger pump at different speeds.

By processing the data in the figure, the maximum and minimum instantaneous flow rates and the flow pulsation rate at different speeds can be obtained, as shown in Table 2. From the calculation results in the table, it can be seen that with the increase of the rotational speed, the pulsation rate of the outlet flow of the plunger pump increases, and the appropriate reduction of the speed can reduce the pulsating characteristic of the pump outlet and reduce the pulsation of the hydraulic system characteristic. 
Table 2 Flow pulsation rate of plunger pump at different rotational speeds.

\begin{tabular}{|c|c|c|c|c|}
\hline $\begin{array}{c}\text { Plunger pump speed } \\
(\mathrm{r} / \mathrm{min})\end{array}$ & $Q_{\max }(\mathrm{L} / \mathrm{min})$ & $Q_{\min }(\mathrm{L} / \mathrm{min})$ & $Q_{\text {mean }}(\mathrm{L} / \mathrm{min})$ & $\begin{array}{c}\delta \\
(\%)\end{array}$ \\
\hline 1000 & 7.35 & 7.10 & 7.225 & 3.46 \\
\hline 3000 & 22.25 & 21.42 & 21.835 & 3.80 \\
\hline 5000 & 37.15 & 35.50 & 36.325 & 4.54 \\
\hline 7000 & 52.10 & 49.40 & 50.75 & 5.32 \\
\hline 9000 & 67.20 & 63.50 & 63.35 & 5.84 \\
\hline
\end{tabular}

\subsection{Inclined Angle of Swashplate}

In the model of the plunger pump, the inclination of the swashplate is set to $3^{\circ}, 5^{\circ}, 7.5^{\circ}, 10^{\circ}$ and $14.5^{\circ}$ respectively,the other parameters remain unchanged. The flow curve of the plunger pump at different inclination of the swashplate is shown in Fig.6.

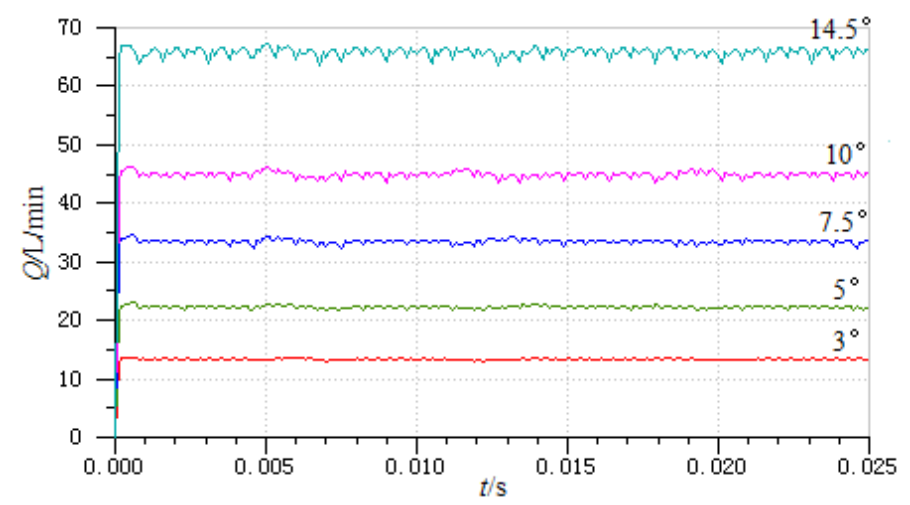

Fig.6 flow pulsation cure of plunger pump at different inclination of inclined plate.

By processing the data in the figure, the maximum and minimum instantaneous flow rates and the rate of pulsation at different speeds can be obtained, as shown in Table 3. From the calculation results in the table, it can be seen that with the increase of the inclination of the swashplate, the pulsation rate of the flow rate of the plunger pump is slightly increased, but the change is not great.

Table 3 Flow pulsation rate of pump at different swashplate angles.

\begin{tabular}{|c|c|c|c|c|}
\hline $\begin{array}{c}\text { inclined angle of } \\
\text { swashplate }^{\circ}{ }^{\circ}\end{array}$ & $Q_{\max }(\mathrm{L} / \mathrm{min})$ & $Q_{\min }(\mathrm{L} / \mathrm{min})$ & $Q_{\text {mean }}(\mathrm{L} / \mathrm{min})$ & $\delta(\%)$ \\
\hline 3 & 13.73 & 13.05 & 13.39 & 5.09 \\
\hline 5 & 22.96 & 21.72 & 22.34 & 5.55 \\
\hline 7.5 & 34.25 & 32.41 & 33.33 & 5.52 \\
\hline 10 & 46.10 & 43.53 & 44.815 & 5.73 \\
\hline 14.5 & 67.20 & 63.50 & 63.35 & 5.84 \\
\hline
\end{tabular}

\section{Conclusion}

Through the theoretical analysis, the equation of motion of the plunger pump plunger, the theoretical instantaneous flow rate and the flow pulsation rate are obtained, and the joint simulation model of the plunger pump is established based on AMESim and ADAMS. The results show that,with the increase of the diameter of the plunger and the increase of the rotational speed, the plunger pump flow pulsation rate has a more obvious increase. As the inclination of the swashplate increases, the pulsation rate of the pump outlet is slightly increased. Using AMESim and ADAMS to establish the co-simulation model of the piston pump, can clearly get its movement law and flow characteristics, which can improve the test efficiency and reduce the costs. 


\section{References}

[1] QI Hai-tao,FU Yong-ling,LANG Yan. Modelling and Simulation of Electrical Servo Variable Dispalcement Plunger Pump Based on AMESim[J].Machine Tool and Hydraulics,2015,3 (5) :115-118.

[2] YANG Zhi-bing, XU Bing, ZHANG Bin. Simulation of axial plunger pump characteristic based on virtual prototype technology[J]. Hydraulics Pneumatics and Seals,2006, (3) :33-36.

[3] TONG Shui-guang, WANG Xiang-bing, ZHONG Wei,etc. Dynamic Characteristics Analysis on Axial Plunger Pump Based on Virtual Prototype Technology[J]. Journal of Mechanical Engineering,2013,49(2): 174-182.

[4] Deeken, Michael. Simulation of the tribological contacts in an axial plunger machine[J]. 2004 ASME International Mechanical Engineering Congress and Exposition, IMECE, 2004 : 71-75

[5] XU Sheng-wu.Plunger Type Hydraulic Pump[M].Beijing:Machinery,1985:22-25.

[6] XU Bing,LI Chun-guang,ZHANG Bin.Research on Pulsation Characteristics of Axial Plunger Pump Based on Virtual Prototype. China[J]. China Mechanical Engineering; 2010,21(10):1203-1207.

[7] YANG Zhi-bing.Research of Virtual Prototype Simulation Technology for Axial Plunger Pump[D].Zhejiang:Zhejiang University, 2006.

[8] WANG Hai-yan,WEI Xiu-ye.Simulation Study on the Flow Pulsation Characteristics of Axial Plunger Pump[J]. Machine Tool and Hydraulics,2014,42（5）:144-148. 